\title{
Erratum to: How effective are plant macrofossils as a proxy for macrophyte presence? The case of Najas flexilis in Scotland
}

Isabel J. Bishop $\mathbb{B} \cdot$ Helen Bennion - Ian R. Patmore - Carl D. Sayer

Published online: 8 September 2017

(C) Springer Science+Business Media B.V. 2017

\section{Erratum to: J Paleolimnol}

DOI 10.1007/s10933-017-9988-5

Unfortunately, there is an error in Fig. 5 in the original publication of the article.

The correct version of Fig. 5 is given below and the original article was corrected.

The online version of the original article can be found under doi:10.1007/s10933-017-9988-5.

I. J. Bishop $(\bowtie) \cdot$ H. Bennion · I. R. Patmore .

C. D. Sayer

Department of Geography, Environmental Change

Research Centre (ECRC), University College London,

Gower Street, London WC1E 6BT, UK

e-mail: i.bishop.11@ucl.ac.uk

H. Bennion

e-mail: h.bennion@ucl.ac.uk

I. R. Patmore

e-mail: i.patmore@ucl.ac.uk

C. D. Sayer

e-mail: c.sayer@ucl.ac.uk 


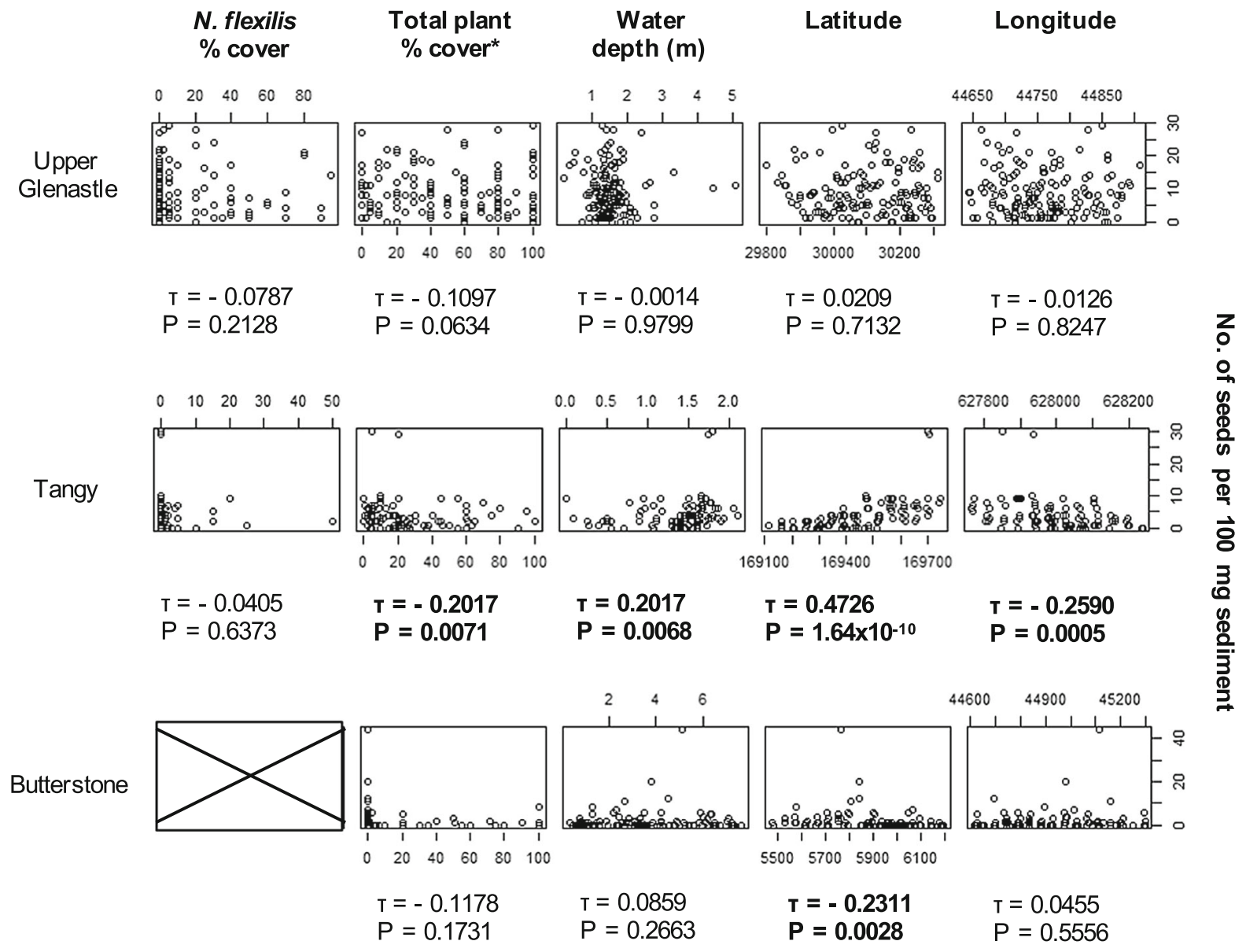

Fig. 5 Scatterplot matrix showing influence of environmental variables on $N$. flexilis seed distribution at each study site. Significant correlations are shown in bold. *Total plant \% cover excluding $N$. flexilis 